\title{
Profiling patterns of fecal 20-oxopregnane concentrations during ovarian cycles in free-ranging southern white rhinoceros (Ceratotherium simum
} simum)

Annemieke Catharina van der Goot ${ }^{\mathrm{a}, \mathrm{b}^{*}}$, Graeme Bruce Martin ${ }^{\mathrm{a}}$, Robert Peter Millar ${ }^{\mathrm{c}, \mathrm{d}}$, Monique Christina Johanna Paris ${ }^{\mathrm{e}}$ and Andre Ganswindt ${ }^{\mathrm{b}, \mathrm{c}}$

\footnotetext{
a School of Animal Biology, University of Western Australia, 1 Stirling Highway, Crawley, WA 6009, Australia

${ }^{\mathrm{b}}$ Endocrine Research Laboratory, Faculty of Veterinary Science, University of Pretoria, Private Bag X04, Onderstepoort 0110, South Africa

${ }^{c}$ Mammal Research Institute, Department of Zoology and Entomology, University of Pretoria, Hatfield, Pretoria 0028, South Africa

${ }^{\mathrm{d}}$ Centre for Integrative Physiology, University of Edinburgh, Edinburgh EH8 9XD, United Kingdom

e Institute for Breeding Rare and Endangered African Mammals, 9 Ainslie Place, Edinburgh, EH3 6AT, Scotland, UK
}

* Corresponding author. Telephone: +61-8-6488-3425. E-mail: avandergoot@zoology.up.ac.za

\begin{abstract}
Unlike their wild counterparts, many white rhinoceros females in captivity fail to reproduce successfully such that current captive populations are not self-sustaining. The causes of the problem are poorly understood. Variation in cycle length and long periods of acyclicity are characteristics of the majority of these non-reproducing females in captivity but it is unknown whether these characteristics are a feature of reproductively successful free-ranging females. This study therefore aimed to monitor cyclic activity in a wild population of southern white rhinoceros at Lapalala Wilderness, South Africa, by
\end{abstract}


measuring the concentrations of immunoreactive fecal progestagen metabolites (fPM). Five adult females were tracked twice per week for 20 months and if located a fresh fecal sample was collected. Reproductive events and group structural dynamics were also recorded and subsequently correlated with the fPM data. The baseline concentration of fPM was $0.69 \pm 0.20 \mu \mathrm{g} / \mathrm{g}$ DW while concentrations during pregnancy were 30 - to 400 fold higher. The females exhibited estrous cycle lengths of $30.6 \pm 7.7$ days and, based on fPM data, gestation length in one female was $502 \pm 3$ days. Year-round monitoring showed no clear evidence of seasonality in ovarian activity. During cyclic luteal activity females were often seen in the presence of a dominant bull. One female stopped cycling after removal of the local dominant bull and luteal activity only returned after a new bull was introduced. This suggests that white rhinoceros females in the wild might need external stimuli from a male to ovulate. These findings indicate that the irregular cyclicity reported for white rhinoceros housed in zoos and animal parks may result from conditions in captivity and account for reduced fertility.

Key words: White rhinoceros, free-ranging, progestagen metabolites, non-invasive hormone monitoring, ovarian cyclicity

\section{Introduction}

The white rhinoceros (Ceratotherium simum), once endemic to sub-Saharan Africa (Prothero and Schoch, 1989), is one of the five species of rhinoceros remaining today, and together with the black (Diceros bicornis), Indian (Rhinoceros unicornis), Sumatran (Dicerorhinus sumatrensis) and Javan (Rhinoceros sondaicus) rhinoceros, faces an uncertain future due to heavy poaching for their horns (Owen-Smith, 1992; Milliken et al., 2009). It has 
been estimated that rhinoceros poaching in Africa has grown by 39\% per year between 2008 and 2013 and, if this rate continues, rhinoceros numbers in Africa will start to decline between 2015 and 2016 (Emslie and Knight, 2014). The southern white rhinoceros population is currently estimated to be over 20,000 with approximately $4 \%$ living in captivity (Emslie and Knight, 2014).

If poaching cannot be controlled, managed breeding may become an important contributor to the global conservation of white rhinoceros as self-sustaining captive and semi-captive populations can provide a valuable genetic reservoir for reintroductions into the wild (Emslie et al., 2009; Milliken et al., 2009). Unfortunately, in most breeding facilities, reproductive rate is poor in the white rhinoceros (Swaisgood et al., 2006; Versteege, 2007; Reid et al., 2012) with less than $50 \%$ of females reproducing even once, and the captive-born generation showing even lower success rates than the wild-caught generation, resulting in a non-selfsustaining population that is declining annually by 3.5\% (Swaisgood et al., 2006; Versteege, 2007).

The reasons for this failure to breed are unclear but do not seem to be due poor male mating behavior or sperm quality (Hermes et al., 2005; Swaisgood et al., 2006). Attention is thus turning to female physiological factors. There have been several studies of the reproductive cycle of captive females based on the measurement of progestagens or their fecal and urinary metabolites (Hindle et al., 1992; Schwarzenberger et al., 1998; Patton et al., 1999; Brown et al., 2001; Carlstead and Brown, 2005). The data revealed distinct variation in cycle length, with short (30-35 days) and long cycles (65-70 days) detected (Hindle et al., 1992; Radcliffe et al., 1997; Schwarzenberger et al., 1998; Patton et al., 1999; Brown et al., 2001) and one female even displayed both cycle types (Patton et al., 1999; Schwarzenberger et al., 1998). However, only the shorter cycles seem to lead to pregnancy (Schwarzenberger et al., 1998; Brown et al., 2001). Furthermore, long periods of anovulation and acyclicity 
have been demonstrated for $60 \%$ of captive females (Schwarzenberger et al., 1998; Patton et al., 1999; Brown et al., 2001; Hermes et al., 2006; Hermes et al., 2012). It is feasible that these prolonged, non-fertile periods are contributing to the development of reproductive pathologies seen in aged females (Hermes et al., 2006; Hermes et al., 2012).

In contrast, much less is known about ovarian activity and its sex hormone correlates for female white rhinoceroses in the wild. Behavioral observations suggest the length of the reproductive cycle is 28 days (Skinner and Smithers, 1990; Bertschinger, 1994). However, there are no physiological data to confirm this, presumably because individual long-term monitoring of physiological markers requiring repeated sampling is usually difficult to conduct in the wild. Thus, it remains unknown whether free-ranging females also show two different cycle lengths or long periods of acyclicity, as seen in captive individuals. This situation can be remedied with the development of a non-invasive sample collection technique for monitoring changes in fecal progestagen metabolites in free-ranging female white rhinoceroses (Goot van der et al., 2013). This technique allows the interpretation of the reproductive pattern and its sex hormone correlates in wild populations of white rhinoceros, and subsequently help to improve breeding strategies for both wild and captive populations.

The main objective of this study was to characterize ovarian cyclicity in free-ranging female white rhinoceroses in a population that lives in its natural habitat and that is reproductively successful. Specifically, the hypotheses tested were: 1) ovarian cyclicity in free-ranging females can be determined using non-invasive fPM; 2) females in the wild only exhibit the single 30-35 day cycle; 3 ) females in the wild show limited periods of acyclicity compared to females in captivity. 


\section{Materials and methods}

\subsection{Animals and study site}

Five adult female southern white rhinoceroses aged 15-25 years were monitored at Lapalala Wilderness, Limpopo, South Africa $\left(23^{\circ} 51^{\prime} \mathrm{S}, 28^{\circ} 16^{\prime} \mathrm{E}\right)$ for a period of 20 months between August 2011 and March 2013. All of the females were proven breeders with no history of reproductive abnormalities, and were likely to go through a period of ovarian cyclicity between two pregnancies during the scope of this study. Females roamed freely in this 36,000 ha privately owned nature reserve in the UNESCO Waterberg Biosphere Reserve and received no supplementary feeding. Paramilitary anti-poaching units effectively patrolled the entire reserve day and night during the course of the study. The region in which Lapalala Wilderness is located has summer rainfall and the annual rainfall ranges from 650 to $900 \mathrm{~mm}$ (Low and Rebelo, 1996). Average maximum temperature is $22^{\circ} \mathrm{C}$ in winter and $32{ }^{\circ} \mathrm{C}$ in summer, and average minimum temperature is $4{ }^{\circ} \mathrm{C}$ winter and $18{ }^{\circ} \mathrm{C}$ in summer (BenShahar, 1987). Two perennial rivers run through the area and the habitat is defined as savanna biome within the classification of Waterberg moist mountain bushveld (Low and Rebelo, 1996). The study was approved by the Animal Ethics and Experimentation Committee of the University of Western Australia (RA/3/600/006).

\subsection{Fecal sample collection and behavioral observations}

Between August 2011 and March 2013, a total of 308 fecal samples were collected from the five females. Each individual was located, identified and observed on a weekly basis. Animals were located in the early morning or late afternoon by footprint tracking combined with individual movement pattern data and identified using physical characteristics such as 
horn size, ear notches and scar tissue (Emslie and Brooks, 1999; Goot van der et al., 2013). Approximately $50 \mathrm{~g}$ of homogenized fresh feces was collected within $30 \mathrm{~min}$ after defecation, placed on ice immediately and, within 1 hour, stored at $-20^{\circ} \mathrm{C}$ until analysis at the Endocrine Research Laboratory, University of Pretoria. Throughout the observation period, physical signs and/or socio-sexual behavior indicating the potential occurrence of estrus, as well as suckling behavior as an indicator for lactation, were documented (Owen-Smith, 1975). In anticipation of a female defecating, observation periods would normally last from 30 minutes to 3 hours. During this period, the physical appearance and behavior of the individual was monitored carefully and signs of mounting, mating, presence of a bull, birth, nursing, suckling calf, swollen vulva and/or vaginal discharge were noted (Owen-Smith, 1975; Patton et al., 1999).

\subsection{Steroid hormone extraction and enzyme immunoassay (EIA)}

Frozen fecal samples were lyophilized, pulverized, and sieved through a nylon mesh to remove fibrous material (Fieß et al., 1999). Pulverized feces $(0.05-0.055 \mathrm{~g})$ were extracted by vortexing for $15 \mathrm{~min}$ with $3 \mathrm{~mL}$ of $80 \%$ ethanol. Following centrifugation for $10 \mathrm{~min}$ at $1500 \mathrm{~g}$, supernatants were transferred into micro-centrifuge tubes and stored at $-20{ }^{\circ} \mathrm{C}$ until assay.

Concentrations of immunoreactive fecal progestagen metabolites (fPM) were measured by enzyme-immunoassay (EIA) technique using an antibody raised against $5 \alpha$-pregnan-3 $\beta$-ol20-one-3-hydroxysuccinyl-BSA and 5 $\alpha$-pregnan-3 $\beta$-ol-20-one-3-hydroxysuccinyl-peroxidase as label (Szdzuy et al., 2006) according to the procedure described by Ganswindt et al. (2002). This EIA has been validated for determining fPM concentrations in southern white rhinoceroses (Goot van der et al., 2013). Cross-reactivities of the antibody are described by 
Szdzuy et al. (2006) and were as follows: 5a-pregnan-3a-ol-20-one, 650\%; 5a-pregnan-3b-ol20-one, 100\%; progesterone, 72\%; 5a-pregnan-3,20-dione, 22\%; Q0 $1 \%$ for 5b-pregnan3a,20a-diol, 4-pregnen-20a-ol- 3-one, 5b-pregnan-3a-ol-20-one, 5a- pregnan-20a-ol-3-one, 5a-pregnan-3b,20a-diol and 5a-pregnan-3a,20a-diol (Szdzuy et al., 2006). Serial dilutions of fecal extracts gave displacement curves that were parallel to the standard curve. Intra- and inter-assay coefficients of variations, determined by repeated measurements of high- and lowconcentration pooled samples, ranged between $9.3 \%$ and $16.5 \%$. Sensitivity of the assay at 90\% binding was 3 pg per well.

\subsection{Data analysis}

Individual baseline values for fPM concentration, in $\mu \mathrm{g} / \mathrm{g}$ dry weight (DW), were calculated using an iterative elimination process as previously described (Brown et al., 1994). In brief; all fPM concentrations of an individual data set exceeding the mean +2 standard deviations (S.D.) were excluded, the average successively recalculated, and the elimination process repeated until no values exceeded the mean +2 S.D. The remaining values yielded the baseline fPM concentrations for the animal under consideration.

Hormone profiles were evaluated on indication of ovarian cyclicity and elevations in fPM concentration were considered to indicate a luteal phase if at least two values exceeded baseline level for at least 2 consecutive weeks (Brown et al., 2001; Ahlers et al., 2012). The end of the luteal phase was defined as the first sample in which fPM concentrations returned to baseline level (Brown et al., 2001). Mean inter-luteal cycle length (the interval between the start of two consecutive luteal phases) was calculated for individuals showing periods of regular ovarian cyclicity. Physical and/or behavioral signs of estrus were aligned with episodes of elevated fPM concentrations. Data are presented as mean \pm SEM. 


\section{Results}

During the course of the study, all five females were always seen in groups of 2-8 animals, with the local dominant bull periodically joining a group for a few days. Three of the five females gave birth during the study period while the other two were already being pregnant at the beginning of the monitoring program. Figure 1 shows the individual longitudinal fPM profiles of the three females (Female 1,2 and 3) that gave birth during the 20-month study period or shortly thereafter (Fig. $1 \mathrm{~A}, \mathrm{~B}, \mathrm{C}$ ). In the two comprehensively monitored pregnancies (female 1 and 2), 400-fold decreases in fPM concentrations preceded parturition (Fig. 1A, B) and, in both cases, a newborn calf was seen with the mother a few days later, confirming successful pregnancy and delivery of viable offspring. In both of these females, postpartum fPM concentrations fluctuated up to 6-fold above baseline values, suggesting luteal activity, but no cyclic pattern could be detected in the 11-12 months following parturition (Fig. 1A, B). During this period, calf nursing and suckling was frequently observed, suggesting that both females were lactating (Fig. 1A, B).

Individual fPM baseline concentrations ranged from 0.41 to $0.92 \mu \mathrm{g} / \mathrm{g} \mathrm{DW}$. Female 3 conceived during the study period and showed regular cycles of luteal activity with a mean inter-luteal cycle length of $31.5 \pm 8.5$ days ( $n=4$ cycles) prior to conception, with the shortest and longest cycle lengths recorded being 22 days and 39 days (Fig. 1C). Its fPM baseline concentration was $0.47 \mu \mathrm{g} / \mathrm{g}$ DW but, during luteal activity, fPM concentrations increased to peaks values of up to $3.58 \mu \mathrm{g} / \mathrm{g}$ DW. No behavioral or physical signs of estrus or mating were observed prior to conception, although she was often seen together with the dominant bull during her period of regular cyclic luteal activity. After conception, fPM concentrations stayed above baseline values, often exceeding luteal phase concentrations from the $3^{\text {rd }}$ month of gestation onwards. 

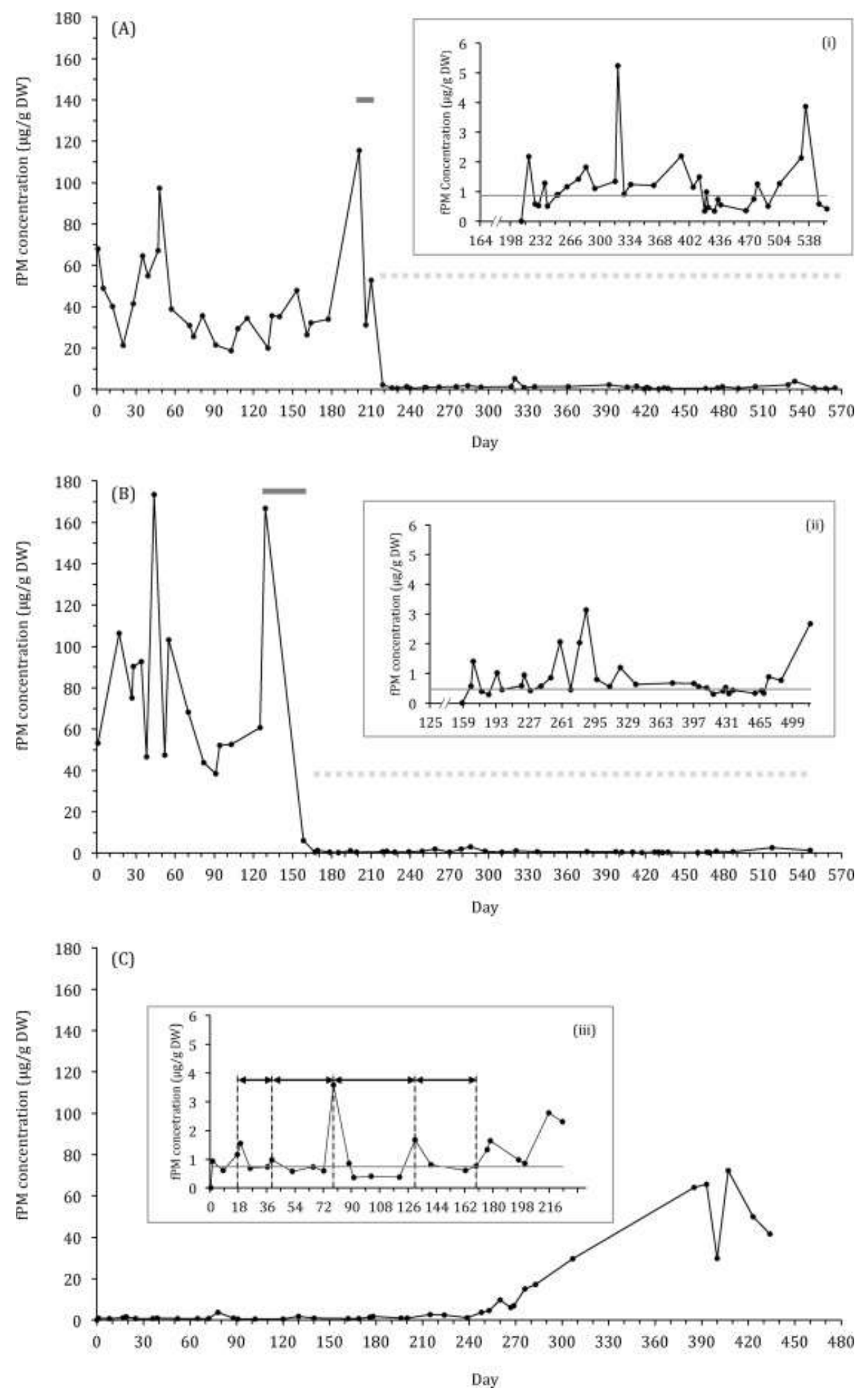

Figure 1 Longitudinal profiles of immunoreactive fPM concentrations (•) for 3 adult female white rhinoceroses. Females 1 (A) and 2 (B) gave birth during the 20 -month monitoring period. The time of parturition (grey bar) was estimated from the appearance of a new calf. The dotted horizontal line indicates lactation anestrus. Female 3 (C) gave birth shortly after the monitoring period in June 2013. The approximate time of conception in this female during the monitoring period is indicated (*). Fecal PM concentrations during the non-pregnant periods are also shown with a different resolution in inserts (i, ii, iii), showing determined cyclic patterns (arrowed). The solid horizontal grey line in inserts indicates individually calculated baseline levels. 

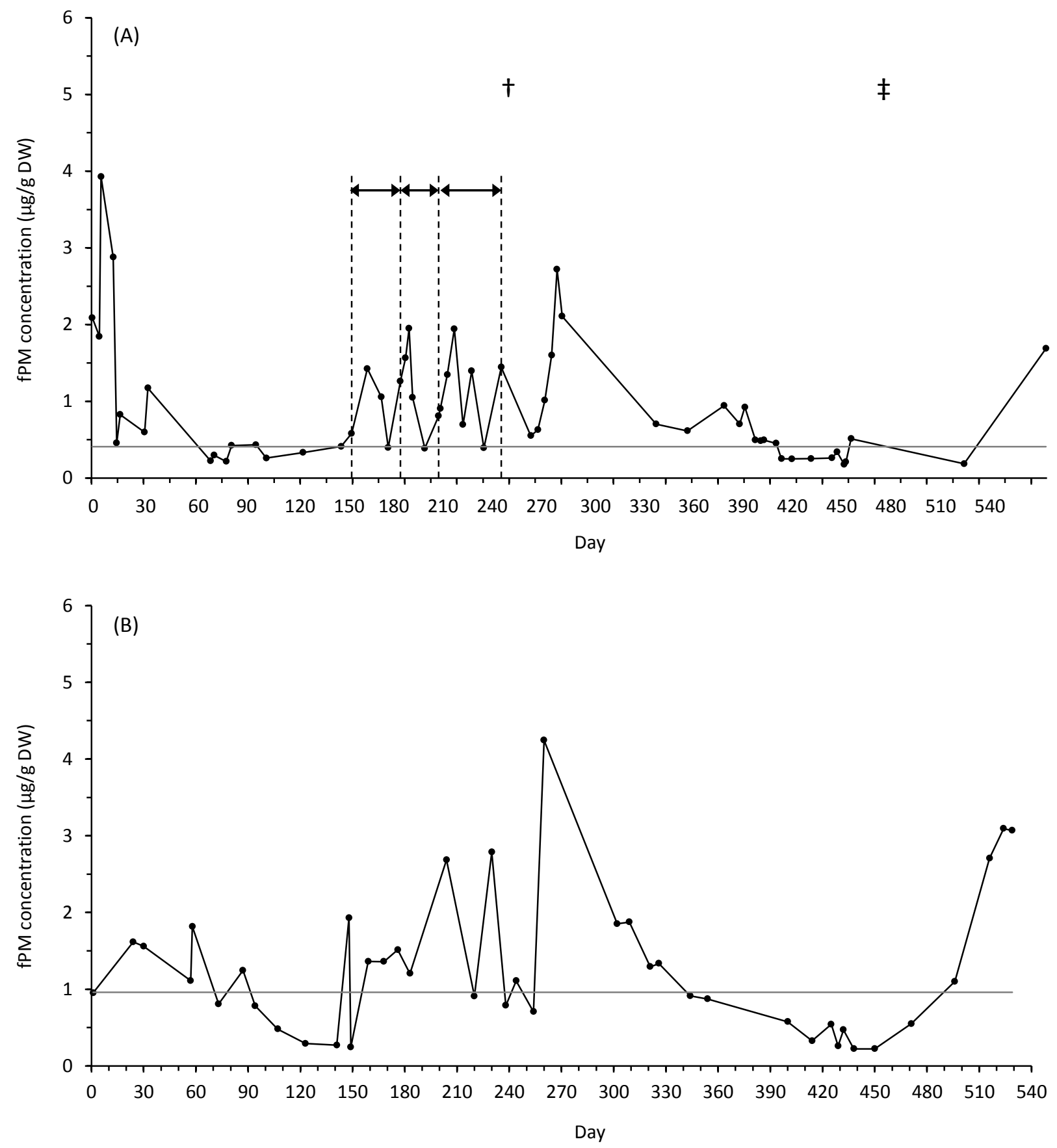

Figure 2 Longitudinal profiles of immunoreactive fPM concentrations $(\bullet)$ in 2 adult female white rhinoceroses. Female 4 (A) and Female 5 (B) were both accompanied by a young calf from the start of the monitoring period. Determined regular cyclic patterns are indicated (arrowed). The solid horizontal grey line indicates individually calculated baseline levels. The dominant bull in the home range of Female 4 was removed from the area (dagger) and a new bull was introduced (double dagger).

Female 4 and 5 did not reflect pregnancy and both had calves, aged 9 and 1 months respectively, at the beginning of the study. Luteal activity was detected in both animals with 
fPM concentrations reaching maximum values of 3.9 and $4.3 \mu \mathrm{g} / \mathrm{g}$ DW (Fig. 2A, B). For female 4 (Fig. 2A), regular cycles could not be detected for the first 5 months of data collection but, subsequently, regular cycles of luteal activity were evident for 85 days (January to April), with a mean inter-luteal cycle length of $29.3 \pm 6.1$ days ( $n=3$ cycles). The shortest and longest cycle lengths recorded during that time were 22 days and 37 days. During these cycles, fPM concentrations reached a maximum value of $3.9 \mu \mathrm{g} / \mathrm{g}$ DW. No indications of behavioral or physical signs of estrus or mating were observed during this time and, towards the end of this period, the dominant bull of this female's home range was removed from the area. After the male was removed, fPM concentrations remained around baseline level. Seven months later a new bull was introduced into the area, but the female moved to an extremely remote area in the reserve, minimizing sampling success. The female returned to its previous home range 5 months later and was observed mating with the newly introduced bull a month later. No regular cycles of luteal activity were detected in female 5 during the course of the study (Fig. 2B).

\section{Discussion}

This study is the first to characterize longitudinal profiles in the fecal concentrations of progesterone metabolites, thus allowing the description of ovarian activity in free-ranging female white rhinoceros. We thus established that non-invasive fPM monitoring techniques could be used successfully in free-ranging individuals to investigate ovarian cyclicity in this species, which is desirable due to inexplicability of the reproductive data for animals held in captivity. We have also established that it is feasible to collect samples on a regular basis from non-collared free-ranging white rhinoceros females in a 36,000 ha reserve. However, the success of sample collection did vary among focal animals in relation to accessibility of 
home range and individual temperaments, so feasibility trials should be carried out before monitoring females in different environments. A white rhinoceros can traverse large distances on a single day and, in the present study, the tracking of one individual often took over 2 hours in a day. To increase success rate and frequency of sample collection, the use of advanced tracking technologies is recommended, especially when tracking in large areas.

A complete pregnancy was monitored in the present study, presenting the first longitudinal fPM profile of gestation in a free-ranging white rhinoceros. The gestation length for this female was 500-505 days ( 16.5 months), a figure that is consistent with previous estimates in the wild based on behavioral observations (480-547 days) (Bertschinger, 1994) as well as estimates for animals in captivity (490-525 days) (Patton et al., 1999). During gestation, fPM concentrations rose to be considerably higher than luteal phase concentrations by the $3^{\text {rd }}$ month of gestation and peak concentrations were 30- to 400-fold higher than baseline values. Similar findings were reported by Schwarzenberger et al. (1998) who mentioned high fPM concentrations in pregnant captive females during the $4^{\text {th }}$ and $5^{\text {th }}$ months of pregnancy, as well as Hermes et al. (2012) who detected a clear increase 2 months after ovulation (Schwarzenberger et al., 1998; Hermes et al., 2012).

In this study, a total of 7 regular cycles were detected, with a mean cycle length $(30.6 \pm$ 7.7 days) that is consistent with lengths derived from behavioral observations (Skinner and Smithers, 1990). Neither of the two females that exhibited regular cycles had long cycles (6570 days), which are commonly present in captive females (Schwarzenberger et al., 1998; Patton et al., 1999; Brown et al., 2001). It is feasible that long cycles reflect reproductive pathology and that females living in the wild without reproductive problems do not show this phenomenon. Diverse factors may be involved such as phytoestrogens in captive diets high in alfalfa (Tubbs, 2012), stress of captivity (Carlstead and Brown, 2005) and absence of appropriate stimulation by a male rhino (Patton et al., 1999; Carlstead and Brown, 2005). 
It is interesting that one female in the wild exhibited a long period of acyclicity that could not be attributed to lactation, as is commonly reported in captive females (Schwarzenberger et al., 1998; Patton et al., 1999; Brown et al., 2001; Hermes et al., 2006; Hermes et al., 2012). Lactation anestrus was visible in this study as an acyclic period until 13 months post partum, in accord with observational studies in the white rhinoceros (Skinner and Smithers, 1990; Owen-Smith, 1992; Schwarzenberger et al., 1993; Brown et al., 2001). Occasionally, concentrations fluctuated towards luteal levels during these periods but no regular cyclic activity was present. One female started displaying regular luteal activity when her calf was 13 months old, however, her regular luteal activity stopped suddenly and she then presented a long acyclic period. In the same month, the dominant bull was removed from the reserve for management purposes. Although other factors that could influence cyclicity—such as stress, age and disease - cannot be ruled out entirely, it is unlikely that this observation was related to reproductive problems, because this female became pregnant shortly after a new adult male was introduced. These observations suggest that long periods of acyclicity are not uncommon in free-ranging white rhinoceros and that ovulation might be influenced by the presence of a dominant male. Similar traits are known in species that do not ovulate spontaneously such as the domestic cat (Felis catus) and camelids (England et al., 1969; Novoa, 1970), the so-called "induced ovulators" that need mating or mounting to elicit a surge of luteinizing hormone (LH) and thus ovulation (Wildt et al., 1981). However, in many induced ovulators, such as the leopard (Panthera pardus) and alpaca (Lama pacos), there is occasionally spontaneous ovulation without copulatory stimuli (England et al., 1969; Fernandez-Baca et al., 1970; Schmidt et al., 1988). In 2001, it was discovered that the Sumatran rhinoceros is an induced ovulator that commonly displays irregular cycling in the absence of mating (Roth et al., 2001). Although most induced ovulators are solitary species, the African lion is an example of an induced ovulator with highly structured social systems (Pusey and Packer, 1987). The 
white rhinoceros has never been considered an induced ovulator (Brown et al., 2001; Roth, 2006), but the present study suggests that external stimuli (contact with a dominant bull) might facilitate ovulation. Moreover, the occurrence of "long cycles" in captivity, perhaps due to luteinized follicles, could be explained, because luteinization of follicles is observed in the Sumatran rhinoceros and several other induced ovulators when ovulation does not occur (Roth et al., 2001). Further investigation, combining ultrasonography and progesterone monitoring, in both captive and wild populations, is necessary to establish whether the white rhinoceros is an induced ovulator or not.

An alternative explanation for the occurrence of a prolonged period of acyclicity that was not related to lactation could be seasonality in ovarian activity, as observed in equids (Brinsko et al., 2010). There is some evidence for reduced reproductive activity during the winter months for free-ranging nulliparous black rhinoceroses (Garnier et al., 2002) and, even in white rhinoceroses, season-related birth peaks have been recorded for the end of the rainy season (Owen-Smith, 1992). However, captive rhinoceroses do not show any seasonal trend in reproduction (Schwarzenberger et al., 1998; Brown et al., 2001), suggesting that seasonal preferences for reproductive activity observed in free-ranging rhinoceroses might be more related to extrinsic factors like food availability (Owen-Smith, 1992) or photoperiod (Garnier et al., 2002; Brinsko et al., 2010).

In conclusion, the fPM data presented in this study on free-roaming white rhinoceros confirms the 'short cycle' of about 30 days as the normal length for ovarian cycles, and that gestation is about 500 days, as found in captive females. However, further studies with larger sample sizes and in different settings are needed to confirm these findings. While a lactation anestrus of about 13 months was confirmed in this study, a period of acyclicity not attributable to lactation was detected in a reproductively healthy free-ranging female, seemingly in association with the removal of a dominant bull, raising the possibility that the 
white rhinoceros is an induced ovulator. Further research that combines behavioral observations, ultrasonography and progesterone monitoring, is required to investigate social and environmental factors regulating cyclic activity in wild populations of white rhinoceros.

\section{Acknowledgments}

We are most grateful to the reserve management of Lapalala Wilderness for permission to conduct research in the reserve. A special thanks is extended to the Head of Natural Resource Management of Lapalala Wilderness, Hermann Müller, for logistic help and support. We thank Tayla Tucker, Monique Rossi and Tamara Keeley for their help in the field and Ms Stefanie Ganswindt, Nettie Engelbrecht and Hettie Rousseau for expert help in the laboratory. Financial support was received by the University of Western Australia, the Mammal Research Institute and Endocrine Research Laboratory, University of Pretoria, the Institute for Breeding Rare and Endangered African Mammals, the AAZK's Bowling For Rhinos, and the SAVE African Rhino Foundation.

\section{References}

Ahlers, M.J., Ganswindt, A., Münscher, S., Bertschinger, H.J., 2012. Fecal 20-oxo-pregnane concentrations in free-ranging African elephants (Loxodonta africana) treated with porcine zona pellucida vaccine. Theriogenology 78, 77-85.

Ben-Shahar, R., 1987. Grasses and habitat relationships on a sour bushveld nature reserve. Vegetatio 72, 45-49.

Bertschinger, H.J., 1994. Reproduction in black and white rhinos: a review. Proceedings of a symposium on rhinos as game ranch animals. Onderstepoort, Republic of South Africa, 9-10 September 1994, 96-99.

Brinsko, S.P., Blanchard, T.L., Varner, D.D., Schumacher, J., Love, C.C., 2010. Manual of equine reproduction. Elsevier Health Sciences. 
Brown, J.L., Wasser, S.K., Wildt, D.E., Graham, L.H., 1994. Comparative aspects of steroid hormone metabolism and ovarian activity in felids, measured noninvasively in feces. Biology of Reproduction 51, 776-786.

Brown, J.L., Bellem, A.C., Fouraker, M., Wildt, D.E., Roth, T.L., 2001. Comparative analysis of gonadal and adrenal activity in the black and white rhinoceros in North America by noninvasive endocrine monitoring. Zoo Biol. 20, 463-486.

Carlstead, K., Brown, J.L., 2005. Relationships between patterns of fecal corticoid excretion and behavior, reproduction, and environmental factors in captive black (Diceros bicornis) and white (Ceratotherium simum) rhinoceros. Zoo Biol. 24, 215-232.

Emslie, R.H., Amin, R., Kock, R., 2009. Guidelines for the in situ re-introduction and translocation of African and Asian rhinoceros. Occasional Paper of the IUCN Species Survival Commission 39, 16.

Emslie, R.H., Brooks, M., 1999. African rhino: Status survey and conservation action plan. IUCN/SSC African Rhino Specialist Group, Gland, Switzerland and Cambridge, UK.

Emslie, R.H., Knight, M.H., 2014. Update on African rhino status and trends: from IUCN SSC African Rhino Specialist Group (AfRSG), 1-6.

England, B.G., Foote, W.C., Matthews, D.H., Cardozo, A.G., Riera, S., 1969. Ovulation and corpus luteum function in the llama (Lama glama). J. Endocrinol. 45, 505-513.

Fernandez-Baca, S., Madden, D.H.L., Novea, C., 1970. Effect of different mating stimuli on induction of ovulation in the alpaca. Journal of Reproduction and Fertility 22, 261-267.

Fieß, M., Heistermann, M., Hodges, J.K., 1999. Patterns of urinary and fecal steroid excretion during the ovarian cycle and pregnancy in the African elephant (Loxodonta africana). Gen. Comp. Endocrinol. 115, 7689.

Ganswindt, A., Heistermann, M., Borragan, S., Hodges, J.K., 2002. Assessment of testicular endocrine function in captive African elephants by measurement of urinary and fecal androgens. Zoo Biol. 21, 27-36.

Goot, van der A.C., Dalerum, F., Ganswindt, A., Martin, G.B., Millar, R.P., Paris, M.C.J., 2013. Faecal progestagen profiles in wild southern white rhinoceros (Ceratotherium simum simum). Afr. Zool. 48, 143151.

Hermes, R., Hildebrandt, T.B., Walzer, C., Göritz, F., Gray, C., Niemuller, C., Schwarzenberger, F., 2012. Estrus induction in white rhinoceros (Ceratotherium simum). Theriogenology 78, 1217-1223. 
Hermes, R., Hildebrandt, T.B., Blottner, S., Walzer, C., Silinski, S., Patton, M.L., Wibbelt, G.,

Schwarzenberger, F., Goritz, F., 2005. Reproductive soundness of captive southern and northern white rhinoceroses (Ceratotherium simum simum, C.s. cottoni), evaluation of male genital tract morphology and semen quality before and after cryopreservation. Theriogenology 63, 219-238.

Hermes, R., Hildebrandt, T.B., Walzer, C., Göritz, F., Patton, M.L., Silinski, S., Anderson, M.J., Reid, C.E., Wibbelt, G., Tomasova, K., Schwarzenberger, F., 2006. The effect of long non reproductive periods on the genital health in captive female white rhinoceroses (Ceratotherium simum simum, C.s. cottoni). Theriogenology 65, 1492-1515.

Hindle, J.E., Most, E., Hodges, J.K., 1992. Measurement of urinary oestrogens and 20 alpha dihydroprogesterone during ovarian cycles of black (Diceros bicornis) and white (Ceratotherium simum) rhinoceroses. J. Reprod. Fertil. 94, 237-249.

Low, A.B., Rebelo, T.G., 1996. Vegetation of South Africa, Lesotho and Swaziland. Department of Environmental Affairs and Tourism, Pretoria, South Africa.

Milliken, T., Emslie, R.H., Talukdar, B., 2009. African and Asian rhinoceroses - status, conservation and trade. A report from the IUCN Species Survival Commission (IUNC/SSC) African and Asian Rhino Specialist Groups and TRAFFIC to the CITES Secretariat. CoP15 Doc. 45.1, 1-18.

Novoa, C., 1970. Reproduction in Camelidae. J. Reprod. Fertil. 22, 3-20.

Owen-Smith, R.N., 1992. Megaherbivores: the influence of very large body size on ecology. Cambridge University Press.

Owen-Smith, R.N., 1975. The social ethology of the white rhinoceros (Ceratotherium simum) (Burchell 1817*). Zeitschrift Für Tierpsychologie 38, 337-384.

Patton, M.L., Swaisgood, R.R., Czekala, N.M., White, A.M., Fetter, G.A., Montagne, J.P., Rieches, R.G., Lance, V.A., 1999. Reproductive cycle length and pregnancy in the southern white rhinoceros (Ceratotherium simum simum) as determined by fecal pregnane analysis and observations of mating behavior. Zoo Biol. 18, 111-127.

Prothero, D.R., Schoch, R.M., 1989. The evolution of perissodactyls. Oxford University Press.

Pusey, A.E., Packer, C., 1987. The evolution of sex-biased dispersal in lions. Behaviour 101.4, 275-310.

Radcliffe, R.W., Czekala, N.M., Osofsky, S.A., 1997. Combined serial ultrasonography and fecal progestin analysis for reproductive evaluation of the female white rhinoceros (Ceratotherium simum simum): Preliminary results. Zoo Biol. 16, 445-456. 
Reid, C.E., Versteege, L., Ludwig, A., Hermes, R., 2012. Analysis of the European captive southern white rhinoceros (Ceratotherium simum simum) population using the International Studbook for the African white rhinoceros (2001-2004) and integrating reproductive health findings. International Zoo Yearbook.

Roth, T.L., 2006. A review of the reproductive physiology of rhinoceros species in captivity. International Zoo Yearbook 40, 130-143.

Roth, T.L., O'Brien, J.K., McRae, M.A., Bellem, A.C., Romo, S.J., Kroll, J.L., Brown, J.L., 2001. Ultrasound and endocrine evaluation of the ovarian cycle and early pregnancy in the Sumatran rhinoceros, Dicerorhinus sumatrensis. Reproduction 121, 139-149.

Schmidt, A.M., Hess, D.L., Schmidt, M.J., Smith, R.C., Lewis, C.R., 1988. Serum concentrations of oestradiol and progesterone, and sexual behaviour during the normal oestrous cycle in the leopard (Panthera pardus). J. Reprod. Fertil. 82, 43-49.

Schwarzenberger, F., Francke, R., Goltenboth, R., 1993. Concentrations of faecal immunoreactive progestagen metabolites during the oestrous cycle and pregnancy in the black rhinoceros (Diceros bicornis michaeli). J. Reprod. Fertil. 98, 285-291.

Schwarzenberger, F., Walzer, C., Tomasova, K., Vahala, J., Meister, J., Goodrowe, K.L., Zima, J., Strauß, G., Lynch, M., 1998. Faecal progesterone metabolite analysis for non-invasive monitoring of reproductive function in the white rhinoceros (Ceratotherium simum). Animal Reproduction Science 53, 173-190.

Skinner, J., Smithers, R., 1990. The mammals of the southern African subregion. University of Pretoria, Pretoria.

Swaisgood, R.R., Dickman, D.M., White, A.M., 2006. A captive population in crisis: Testing hypotheses for reproductive failure in captive-born southern white rhinoceros females. Biological Conservation, 129, 468476.

Szdzuy, K., Dehnhard, M., Strauss, G., Eulenberger, K., Hofer, H., 2006. Behavioural and endocrinological parameters of female African and Asian elephants Loxodonta africana and Elephas maximus in the peripartal period. International Zoo Yearbook 40, 41-50.

Tubbs, C., 2012. Activation of southern white rhinoceros (Ceratotherium simum simum) estrogen receptors by phytoestrogens: Potential role in the reproductive failure of captive-born females? Endocrinology $153,1444-$ 1452.

Versteege, L., 2007. White Rhinoceros European Endangered Species Program Annual Report. 
Wildt, D.E., Chan, S.Y.W., Seager, S.W.J., Chakraborty, P.K., 1981. Ovarian activity, circulating hormones and sexual behavior in the cat. I. Relationships during the coitus-induced luteal phase and the estrous period without mating. Biology of Reproduction 25, 15-28. 